\section{Golgi method for old formol-fixed human foetal tissue}

DOROTHY MEYER AND SERGE DUCKETT From the Departments of Neuropathology and Neurology, Indiana University Medical Center, Indianapolis, Indiana, and Departments of Neurology and Pathology of Jefferson Medical College of The Thomas Jefferson University, Philadelphia, Pennsylvania, USA

The Golgi method can be successfully applied to human embryonic and foetal nervous tissues which have been fixed in formol for years provided the scalp and skull of the specimen were opened originally for proper fixation. The following method is a variation of the Golgi method which has proved successful:

1 Wash the complete embryo or foetus (up to the age of 12 weeks-crown-rump length $87 \mathrm{~mm}$ ) in running tap water for 24 hours. The brains of older specimens must be cut into slices about $1 \mathrm{~cm}$ thick.

2 Leave the washed tissues in distilled water for one to two hours.

3 Place the tissues in a Golgi solution (1 part $1 \%$ osmic acid plus 4 parts $3 \%$ potassium dichromate) in the dark for three days.

4 Wash the tissues carefully in distilled water until the water is not stained yellow.

5 Repeatedly wash the tissues in a $0.75 \%$ silver nitrate solution until the fluid is not stained red. Then leave the tissues in a fresh silver nitrate solution for two to three days.

Received for publication 18 November 1971.

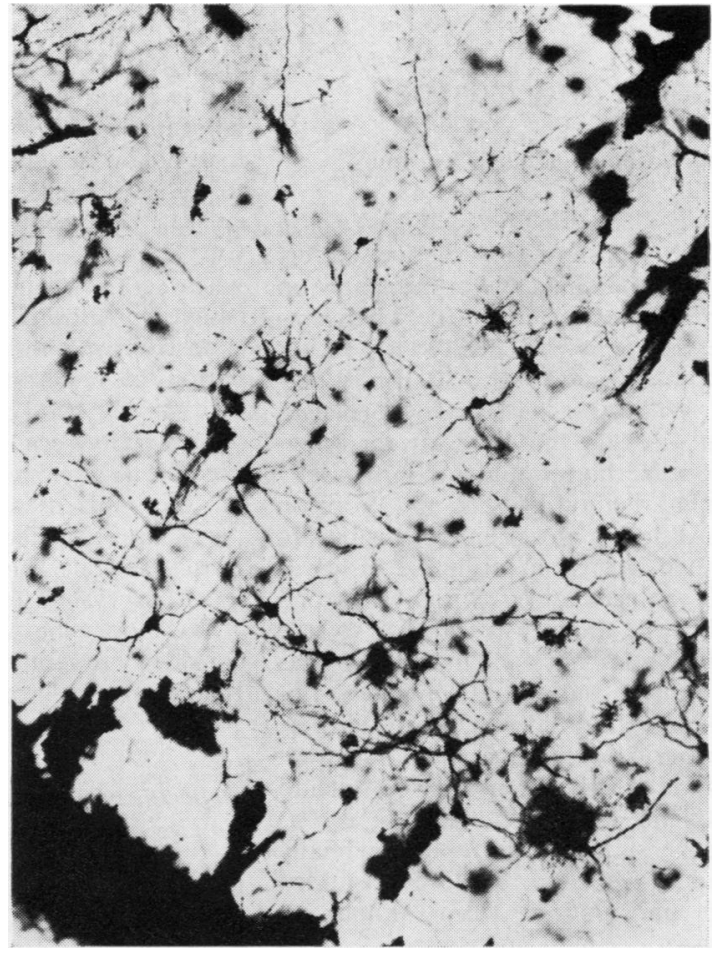

Fig. Neuroblasts in the brain stem of a 10 week old foetus (crown-rump $0.5 \mathrm{~cm}$ ).

6 Wash the tissues carefully in distilled water and brush off carefully and completely the dark brown red precipitate on the surface of the specimen.

7 Repeat steps 3, 4, 5, and 6 twice.

8 Dehydrate and embed in celloidin. 